\title{
Financial Risks in the Conditions of Unstable Market Economy
}

\author{
Ellina Pakhucha ${ }^{1}$, Iryna Sievidova ${ }^{2 *}$, Iryna Siadrysta ${ }^{3}$, Leonid Mohilevsky ${ }^{4}$, \\ Tamila Oliynik ${ }^{5}$, Olga Bogdanovych ${ }^{6}$
}

\begin{abstract}
The necessity and significance of financial risks, which are a constant factor in the activity of any enterprise, are substantiated. It is established that for a broader understanding of the essence of financial risk it is necessary to consider it as a cumulative risk of the enterprise. The growing impact of financial risks on the results of financial and economic activities is associated with the uncertain economic situation, the instability of financial market conditions, the rapid introduction of new financial technologies and financial instruments, expanding the scope of financial relations of the enterprise.

A system of financial ratios has been formed to quantify the risk of enterprises of different sizes, namely for large, medium and small enterprises, which most accurately reflect the current financial situation. Has been proven that the growing pressure of the crisis and insecurity on the part of the state will lead to the transition from the crisis in which enterprises are today, to a state of economic bankruptcy. It is established that the first place among the blocks of financial coefficients of risk assessment of enterprises is occupied by the block of business activity, then the block of profitability indicators, the block of liquidity indicators, the final block of capital structure. For each of the defined blocks the directions of increase, or optimization that will provide financial stability of the enterprise are presented.
\end{abstract}

Key Words: financial risk, financial stability, financial risk minimization, profitability, trade enterprises.

\section{Introduction}

Carrying out entrepreneurial activity is directly associated to risk, business entities receive the greatest profit precisely from activities with an increased level of risk, at the same time and the threat of loss of financial stability of the enterprise is growing. Mostly, risks are the understood as the probability of failure or an event with negative consequences in the future, that is, any activity that leads to a loss of any type called a risk. From the point of view of economic interpretation, risk is the likelihood of obtaining a negative result (obtaining financial costs or additional and unforeseen expenses, non-

\footnotetext{
| ${ }^{1} \mathrm{Ph} . \mathrm{D}$. of Economics, associate professor of the Department of Applied Economics and International Economic Relations, Kharkiv National Agrarian University named after V.V. Dokuchaev, Ukraine.

2Doctor of Economics, professor of the Department of Legal Support of Economic Activity, Kharkiv National University of Internal Affairs, Ukraine. *Corresponding Author.

3Ph.D. of Law, associate professor of the Department of Legal Support of Economic Activity, Kharkiv National University of Internal Affairs, Ukraine.

${ }^{4}$ Doctor of Law, professor, Vice-rector of Kharkiv National University of Internal Affairs, Ukraine.

${ }_{5}^{5}$ Doctor of Law, associate professor of the Department of Legal Support of Economic Activity, Kharkiv National University of Internal Affairs, Ukraine.

${ }^{6} \mathrm{Ph} . \mathrm{D}$. of Economics, Senior Lecturer of the Department of Agrologistics and Supply Chain Management, Kharkiv Petro Vasylenko National Technical University of Agriculture, Ukraine.
} 
receipt of planned income, and not covering expenses, loss of profit, loss of market share), which arises under uncertain economic and financial conditions.

There is a definition of "financial risk" of an event that can lead precisely to financial losses. Financial risk is a type of hazard that can lead to loss of capital for stakeholders.

According to the classification of risks, divided them into pure and speculative. Net risks involve the possibility of negative or no effect. Whereas speculative ones provide for the possibility of obtaining both negative and positive results.

In turn, it is attributed financial risks to the group of speculative risks, which makes it possible to expect, in the uncertain conditions of financial and economic activity, to make a profit. Financial risks are interconnected and are a complex set of cause and effect relationships. Financial risks also include operational and investment risks.

Therefore, for a broader understanding of the essence considered it financial risk as the overall risk of the enterprise. In the overall risks of an enterprise, financial risks play the most important role. The growing role and influence of financial risks on the results of financial and economic activities is associated with an uncertain economic situation, instability of market conditions, the rapid introduction of new financial technologies and financial instruments, and the expansion of the scope of financial relations of the enterprise.

The financial position, and, consequently, the appearance of financial risk, may also depend on the type of activity of commodity producers, because each economic sector has different factors of influence and the level of dependence on the factors of influence of the macroeconomic environment.

When assessing the financial risks of an enterprise's goals, it is important to take into account what its activities aiming at. Considering that, the goals of the enterprise change depending on a certain period and the development of the enterprise itself. The main purpose of assessing financial risks is aiming at determining whether there will be large losses from certain decisions. More than the end results, that cause financial risks.

Due to the unstable economic and financial situation, the risk of insolvency may arise in most enterprises. The most important of the financial risks are inflationary, currency and credit. Particularly acute is the issue of leveling risks that do not depend on the activities of the enterprise and arise owing to the external environment. For the government, financial risk can mean the inability to control monetary policy and default on bonds or other debt issues.

Financial risk also concerns the possibility that the government will lose control of its monetary policy. Will not be able or unwilling to control inflation and non-payment of its bonds or other debt issues. Organizations also face the possibility of default on the debts they take on. However, they can also fail at entrepreneurship, which puts a financial burden on the business.

Financial markets face financial risk through various macroeconomic forces, changes in market interest rates and the possibility of default by economic sectors. Executives face financial risk when making decisions that could jeopardize their income or ability to pay off debt.

Consequently, identifying and justifying financial risk is one of the most difficult and least accurate in solving problems in a rapidly changing present. However, the most 
accurate assessment of the possibility of identifying financial risk will help mitigate risks and find additional financial resources in time to achieve the main goal of the enterprise and solve the assigned tasks at all stages of its life cycle.

\section{The Market Research Conducting - A Literature Review}

According to the Law of Ukraine (Law of Ukraine, 2000), entrepreneurship is a direct, independent, systematic, at its own risk, activity to produce products, perform work, provide services for the purpose of making a profit, carried out by individuals and legal entities registered as subjects of entrepreneurial activity in the manner prescribed by law.

The efficiency of any enterprise is associated with risks that arise under the influence of external and internal factors and directly affect the development of the enterprise itself and its financial position. Indeed, as shown in (Sievidova, 2018), in the wholesale market, no enterprise or private manufacturer against negative results insured, because it cannot set a price higher than other market participants can. Because end buyers always have information about the price level and choose those market entities that offer lower prices.

In work (Dermenzhi, 2018), the risks directly related to internal and external factors are investigated. Special methods have been developed. The most expedient among which is the normative method, the advantage of which is the ease of calculations due to already defined indicators that take into account the influence of inflation, credit rates and other external factors on the financial activity of the enterprise. The method for assessing financial stability characterizes the change in the main financial indicators; however, it is narrower than the standard method. Static methods require sufficient knowledge of the past, but the results obtained will not always be true, especially when used to determine predictive values.

The work (Dombrovska, 2016) presents the sequence of risk analysis at the enterprise and introduces the procedure for the mathematical calculation of the risk level indicator. The main areas of risk of the enterprise's activity are highlighted and the ratio of long-term and current obligations and security of enterprises is highlighted. Measures are proposed to neutralize financial risks in business.

The work (Tkachuk, 2015) systematizes the main methods for identifying possible risks of an enterprise. The groups of accounting and analytical support are highlighted, which help to identify internal threats of the enterprise. The composition of each classification group of accounting and analytical support is shown and their general characteristics are given. It is concluded that the existence of reliable information allows you to quickly make optimal decisions to ensure the financial and economic security of the enterprise.

In (Chomicz-Grabowska, Orlowski, 2020), the dynamic interaction and feedback effects between the risks of the financial market and key variables of macroeconomic stability, including the unemployment rate, general inflation, and market inflation expectations, which are reflected by the break-even, are investigated. The authors argue that market risk should play a stronger role in macroeconomic modeling and forecasting than has been recognized to date. 
The article (Gherasymova, 2016) presents the consequences of ineffective financial risk management and systematizes recommendations for minimizing financial risks to ensure an appropriate level of economic security of an enterprise. The given mechanism for minimizing financial risks, which is based on the use of a set of methods and techniques to reduce possible financial losses in order to ensure its financial stability.

In work (Shura, 2016), a qualitative assessment of financial risks was carried out, the results of which revealed the main types of financial risks that most negatively affect the financial position of an enterprise: the risk of loss of financial stability and investment risk. An algorithm has been developed to neutralize these types of risks in the future based on the use of the advantages of a public joint stock company in the possibility of additional issue of shares and obtaining an additional amount of equity capital for the implementation of effective investment projects.

The authors of (Bragoli at al., 2020) identified the relationship between innovative cost models and the business cycle, which, according to the study, is very weak in the absence of credit constraints and financial vulnerability. The crisis alone and financial vulnerability alone do not change this weak link. The latter becomes extremely pro-cyclical in only one case: when the company is financially vulnerable and they face tight credit conditions.

In the article (Aref'jeva at al., 2019), the authors summarized the main directions of financial risk management, presented the mechanisms of financial stabilization of the enterprise (operational, tactical, strategic), proposed a system for the prevention of financial risks. The authors noted that in order to minimize financial risks, the management of an enterprise must rely on scientific research and skillfully combine known methods and use them in the ongoing financial and economic work of the enterprise. That will help to improve the solvency and improve the financial stability of the enterprise, increase the efficiency of production and business activities and make the financial management of the enterprise more efficient.

The study (Vitalina, Delasa at al., 2015) suggests that the system of indicators for measuring the financial security of an enterprise should include at least the following main areas of research: analysis of financial and economic activities, operational analysis, cash flows and entrepreneurial activities of entrepreneurial risk. The authors also propose the establishment of a list of the main studied in accordance with the characteristics of the enterprise, and the calculation of a generalizing integral index.

The article (Nazari, Zamani, 2018) explores the methods of selection and implementation of financial strategies, the quality of company management, the adoption of appropriate strategies for financial risks, an increase in overall risk and total production. The authors presented appropriate strategies to reduce financial risks, overall risk, and increase production.

In the field of artificial intelligence (Pengbo, Hanyu, 2018), attempts have been made to recognize financial risk using Internet efficiency technologies, which make it possible to assess financial risks and develop measures to minimize their impact on the efficiency of an enterprise.

An approach to the analysis of risks was proposed (Portovaras, 2018), which allows identifying the risk areas of financial and economic activities of enterprises, analyzing the influence of risky-producing factors on the specific results of enterprises' 
activities, as well as developing effective measures to manage them. Focusing on these factors refutes the analysis procedure and, accordingly, increases the efficiency of risk management.

In the research (Yuxiao at al., (2020), the authors examined the impact of ISO 14001, an international environmental management accreditation, on long-term financial risk and firm sales growth. This study is one of the first studies to show that environmental accreditation is a trade-off between reducing financial risk and improving sales growth.

A systemic indicator of risk was proposed (Mihoci at al., (2020), taking into account the links and interdependencies between financial institutions using information on the final results. The Financial Risk Meter (FRM) is based on minimal absolute regression and quantile regression of the choice operator, designed to capture the joint movements of events. The main focus of FRM is focused on understanding the characteristics of active datasets and representing interdependencies in network topology. In practice, FRM is applied to time series returns of selected financial institutions and macroeconomic risk factors. Thus, FRM puts the bottom line in terms of financial risk factors.

In the work by the authors (Dervis, Kirikkaleli, 2019), the study is devoted to the causal relationship between financial risk and economic risk using wavelet coherence tests. The results of the wavelet coherence support Schumpeter's hypothesis, since the obtained data clearly show how important the financial risk is, foresees the economic risk in Greece during 1990-2018.

Research (Kuzjminecj, Pereghnjak, 2017) shows that risk management includes an analysis of possible options that are characteristic for different quantitative assessments of risk and possible variations of its types and identification of possible factors affecting the overall level of financial risk, as well as ranking them by importance. The stages of the process of financial risk management at enterprises have been determined. The methods of their assessment and methods of financial risk management are indicated.

In (Sosnovska, Zhytar, 2018), it was determined that the choice of principles and methods for building financial stability depends on such financial interests of business entities as the formation of flexible financial potential, optimization of the capital structure, increasing investment attractiveness, maximizing profits and increasing the market value of an enterprise. It has been proven that the result of building flexible financial stability is to ensure an appropriate level of financial security of an enterprise by identifying, quantifying, neutralizing, minimizing and controlling its financial risks.

In (Orlyk, 2016) that the degree of influence of financial risks on the results of the financial and economic activities of an enterprise is growing was established and is associated with the rapid volatility of the economic situation in the country, market conditions, to the expansion of the sphere of financial relations, the emergence of new financial technologies and instruments and a number of other factors, and methods of influencing directions of regulation of the degree of financial risks .

In (Tsintsadze, at al., 2019) to the impact of credit and operational risks on the financial results of the bank and developed recommendations to improve the efficiency of risk management are investigated.

Research (Lewis, 2020) is aiming at studying methods to reduce financial risk, focusing on the management of their own investment portfolio. Several methods have 
been identified for effective portfolio management, including: understanding financial risks; diversification of your capital; planning the time horizon.

The article (Shyshkina, 2016) the essence of risk management, based on the identification and assessment of risks and the development of measures to minimize and neutralize the negative consequences of risks summarizes. Of identifying threats and interests of a business entity as a key element of risk assessment has been substantiated to the importance. Methods for minimizing financial risks are systematized and their theoretical and applied aspects of use are determined.

The program for managing the financial risks of the enterprise has been improved (Bjelousova, 2017). The introduction of a program and a complete list of stages of financial risk management in its financial activities should ensure stable and predictable activities of the enterprise. Using the proposed version of the program allows you to constantly control and monitor the process of financial risk management at enterprises.

The article builds a model of preventive diagnostics of the financial risk of a state enterprise, based on the indicators of the financial condition of the enterprise. It has been substantiated that the resulting indicator, which reflects the level of financial risk of an enterprise, is the profitability ratio of property. Based on the results of the constructed model, the priority of the influence of financial condition indicators on the level of financial risk of a state enterprise was established (Pustovghar, Rudachenko, 2019).

The significant contribution to the study of this problem, it should be noted that some aspects remain insufficiently studied considering. More in-depth studies of the state and trends in the development of financial risk and its impact on financial stability are required, despite the emergence of new unpredictable factors. The essence of the study is to study the optimal algorithm for determining financial risk and assessing the general condition, taking into account the factors of influence. Systematic monitoring of financial risks in modern conditions is an important tool to reduce its impact or neutralize negative consequences to ensure financial stability and competitiveness.

The study uses to determine the current financial condition of enterprises by assessing financial risks. Therefore, we set the following aims to achieve this task: to determine an algorithm for assessing financial risks, to analyze the current state of the financial sphere of business, to determine priorities in financial stability management in order to avoid financial risks in the modern conditions of functioning and development of business entities.

\section{Specification and algorithm for assessing the financial risks of enterprises}

Financial risk is a constant factor in every business, and the best way to manage these risks depends on the industry. A financial risk assessment can help determine the level of risk specific to a business, prioritize those risks, develop ways to avoid them, and identify steps to manage them if they arise. To develop a solution to reduce financial risk, you need to identify and analyze financial risks, and then create a financial risk management plan.

Traditionally, there are two types of financial risk assessment, qualitative and quantitative. Qualitative methods for assessing financial risks include identifying risks, determining the causes of their occurrence and possible risk areas, as well as negative 
consequences from making a risk decision or possible benefits (Zorina, 2011). Comparing the methods of quantitative assessment of financial risk, it was determined that the level of risk may vary depending on the selected assessment method. Among the methods of quantitative assessment of financial risk, we used the expert method. This method was chosen due to the fact that it allows you to obtain the necessary results for some criteria, obtained as a result of financial and economic experience and a limited amount of information (Sievidova, 2018). We identified the types of financial risks of financial and economic activities of wholesale enterprises. The experts identified a set of internal and external risks. The most striking manifestation in the activities of wholesale trade enterprises among internal risks is the risk of business activity $(28.6 \%)$ and the risk of capital structure $(14.7 \%)$.

To calculate the integral index for quantitative and qualitative assessment of financial risk and its further assessment with the definition of the level of the crisis with a graduated scale, we used the method (Ugrimova, at al., 2016). It maximally takes into account the necessary indicators for determining the level of financial risk.

The object under study is described by a system of pointers $\mathrm{x}_{1}, \mathrm{x}_{2}, \mathrm{x}_{3}, \ldots, \mathrm{x}_{\mathrm{n}}$ in the dynamics for the period $t_{1}, t_{2}, \ldots$ tn, represented by the matrix "time indication". Characterize the elements of the value of the indicator at the time $t$, combined into blocks $\left(\mathrm{y}_{k}\right)$, which fragmentarily determine the level of financial potential. The range of variations in the potential level of financial stability is as follows: 0 - 1 (financial risk also varies depending on these measures). The integrated risk assessment is calculated by all the set of selected indices, which reflects a fragment (block) of the financial condition and shows its proximity to the sample (targeted). There are two stages of calculation of the integrated index.

Comprehensive assessment within the units is performed at the first stage, allows for a qualitative risk assessment and to assess the level of crisis.

Calculation of the standard deviation of the $j$-th probe of the $k$-th block:

$$
\sigma_{j k}=\sqrt{\frac{\sum\left(x_{i j k}-\overline{x_{j k}}\right)^{2}}{N}},
$$

where, $x_{\mathrm{ijk}}$ - the value of the $j$ - th indicator of the $k$-th block in the ti year of the study period;

Calculation of standard values of indicators:

$$
Z_{i j k}=\frac{x_{i j k}}{\sigma_{j k}}
$$

The calculation of the standard reference values:

$$
Z_{i j k}^{*}=\frac{x_{i j k}^{*}}{\sigma_{j k}}
$$

Assessment of reference values of indicators ${ }^{*} x_{j k}$ - the reference value of the $j$-th indicator of the k-th block;

Determining the weight of indicators in a comprehensive assessment: 


$$
\alpha_{j k}=\frac{Z_{j k}^{*}}{\sqrt{\sum_{i=t}^{n}\left(Z_{j k}^{*}\right)^{2}}},
$$

Calculation of the value of the potential function over the years:

$$
y_{j k}=\sum_{j=1}^{n} \alpha_{j k} Z_{i j k}
$$

Calculation of the reference value of a potential function:

$$
y_{k}^{*}=\sum_{j=1}^{n} \alpha_{j k} Z_{j k}^{*}
$$

Calculation of a comprehensive assessment of financial potential:

$$
C_{i k}=\frac{y_{i k}}{y_{k}^{*}},
$$

The second stage of calculating the integrated index includes financial potential (risk assessment).

Calculation of weight of blocks:

$$
\widetilde{\alpha_{k}}=\frac{y_{k}^{*}}{\sqrt{\sum_{k=1}^{m}\left(y_{k}^{*}\right)^{2}}},
$$

Calculation of the value of the potential function over the years:

$$
\widetilde{y_{t}}=\sum_{k=1}^{m} \widetilde{\alpha_{k}} y_{i k},
$$

Calculation of the reference value of a potential function:

$$
\widetilde{y^{*}}=\sum_{k=1}^{m} \widetilde{\alpha_{k}} y_{k}^{*}
$$

Calculation of an integrated assessment of financial potential:

$$
\widetilde{c_{l}}=\frac{y_{i}}{\widetilde{y}^{*}}
$$

Calculation of the level of financial risk:

$$
p_{i}=1-C_{i}
$$

The next stage is a qualitative assessment of financial risk:

$\mathrm{P}=(0.75-1)$ - catastrophic level of financial risk;

$\mathrm{P}=(0.50-0.74)$ - critical financial risk;

$\mathrm{P}=(0.25-0.49)$ - allowable financial risk;

$\mathrm{P}=(0-0.24)$ - risk-free activity.

Financial indicators were selected on the basis of available financial statements, and were calculated according to a single methodology, relative indicators were determined, which were measured as a percentage or share of the unit and had the same direction. The 
value of indicators in the potential function of finance, potential integrated assessment, as well as in the potential function of the relevant block of system indices is analyzed with their subsequent ranking either by blocks or within blocks, priorities in decision-making concerning their activities are determined, risks are minimized.

Financial indicators were determined for each block, which were represented by medium and small enterprises (Fig. 1), taking into account the factor loads of both indicators and blocks.

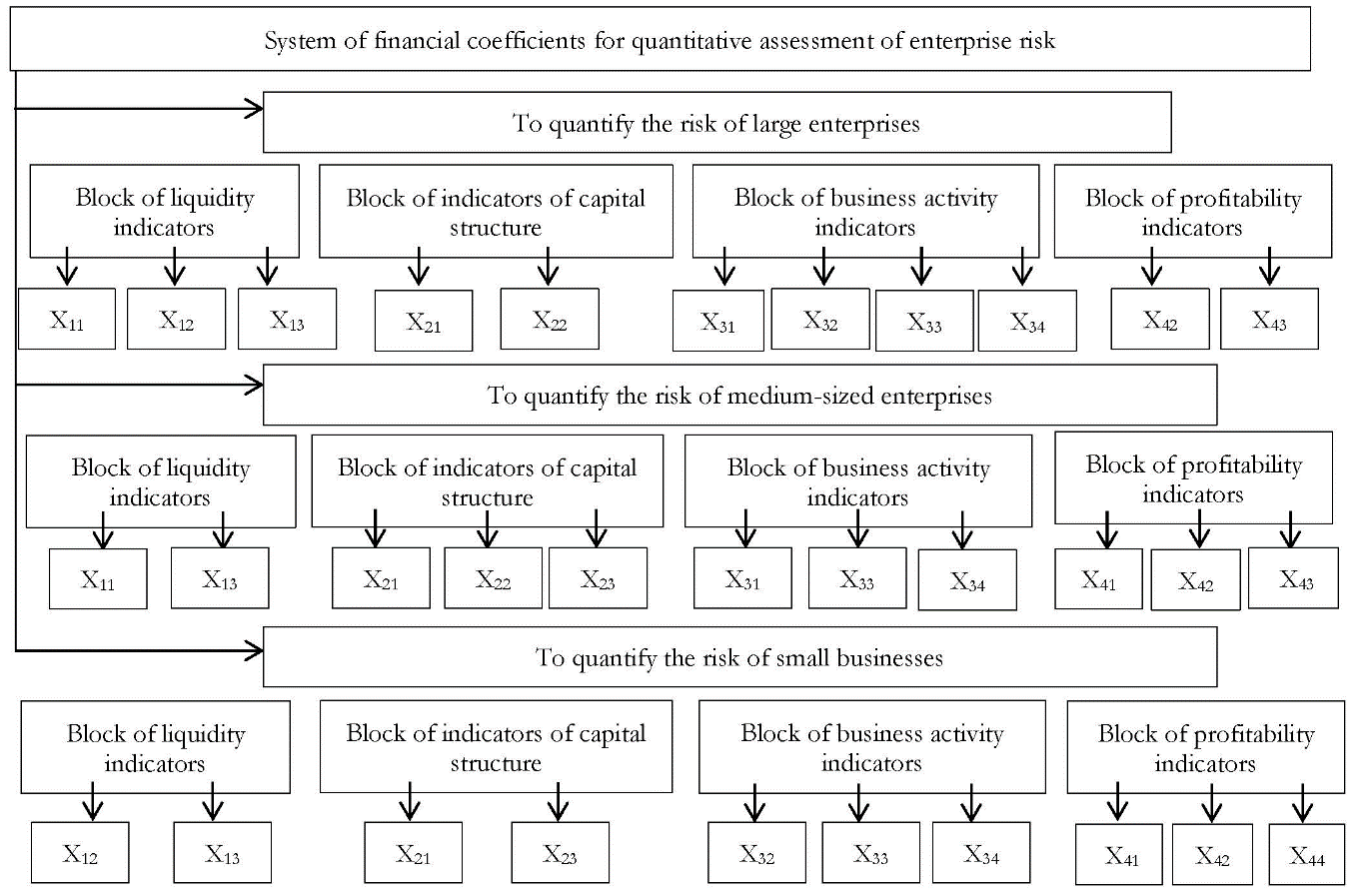

Fig. 1 The system of financial ratios for quantitative risk assessment of enterprises of different sizes.

The reference values of the coefficients were determined for each enterprise according to the standard, depending on the goals and financial condition of the enterprise, the maximum, average or normative value of the financial coefficient can be taken.

Selected indicators for financial risk assessment objectively reflect as industry specifics of enterprises:

$\mathrm{X}_{11}$ - absolute liquidity ratio;

$\mathrm{X}_{12}$ - quick liquidity ratio;

$\mathrm{X}_{13}$ - coverage ratio;

$\mathrm{X}_{21}$ - coefficient of autonomy;

$\mathrm{X}_{22}$ - coefficient of stability;

$\mathrm{X}_{23}$ - equity maneuverability ratio;

$\mathrm{X}_{31}$ - asset turnover ratio;

$\mathrm{X}_{32}$ - inventory turnover ratio;

$\mathrm{X}_{33}$ - receivables turnover ratio;

$\mathrm{X}_{34}$ - accounts payable turnover ratio; 
$\mathrm{X}_{41}$ - profitability ratio of sales;

$\mathrm{X}_{42}$ - cash flow adequacy ratio to repay the debt;

$\mathrm{X}_{43}$ - return on assets for income before tax and interest payments;

$\mathrm{X}_{44}$ - return on assets for net income.

For a qualitative assessment of financial risk at a certain point in time, a gradation of the risk scale is formed, which is universal in the process of graduation of the risk scale, the proposals (Ghranaturov, Lytovchenko, 2004) were used.

The gradation of the scale of financial risk begins with the designation $0-0.24$ and indicates the missing threat of a crisis, indicates that the company has a sufficiently high level of profitability and business activity and high financial potential (0.75-1). The next scale has a value of $0.25-0.49$ and indicates a weak threat of a crisis indicates that the economy retains its economic viability, however, one of the blocks does not correspond to the reference one, there is a threat of a complete loss of profit from sales, the level of potential is within $0.74-0.50$. The crisis state corresponds to the gradation of the scale $0.50-0.74$, indicating that the economic feasibility of the enterprise is under threat, the rather low level of business activity, the amount of accounts receivable and the duration of the period of its turnover are growing, the potential level is within the limits of 0.49-0, 25. The last value in the gradation of the financial risk scale has the designation 0.75-1.00 and indicates the state of the economic bankruptcy of the enterprise. The farm has problems with the settlement of obligations, the loss of capital and property is possible. The potential level is within the range of 0.24-0.

\section{Application of the algorithm for assessing financial risks to determine the development trends of the current financial condition of enterprises.}

Studying the types of financial risks, it was found that some of them are the same for most types of entrepreneurial activity. In our study, we will call them objective. Existing approaches and methods can be used to manage these risks. At the same time, based on the characteristics of the type of activity, it is possible to single out the risks inherent only to it. These financial risks in the context of our research will be called specific. To manage them, it is necessary to analyze the possibility of applying existing approaches to risk management or develop new approaches. The problem of assessing the specific financial risks of brokerage activities requires more detailed consideration (Zaika, at al., 2020).

Measuring the financial performance of enterprises and their assessment are among the main identifiers of the overall success of enterprises in the market. Knowledge of indicators that reflect the financial performance associated with the dynamic environment in which enterprises operate, as well as with the constant pressure of the environment for improvement, is a key element in increasing competitiveness and strengthening market position. Although the use of non-financial metrics is still more widely promoted, financial metrics can actually and accurately assess the health of an enterprise based on its past development.

Based on this issue, we assessed the financial performance of enterprises operating in the wholesale trade. The financial results before taxation of activities were investigated as an indicator characterizing the potential for generating profits of wholesale trade 
enterprises with distribution to large medium-sized and small enterprises, since the studied enterprises belong to this type of economic activity (Fig. 2).

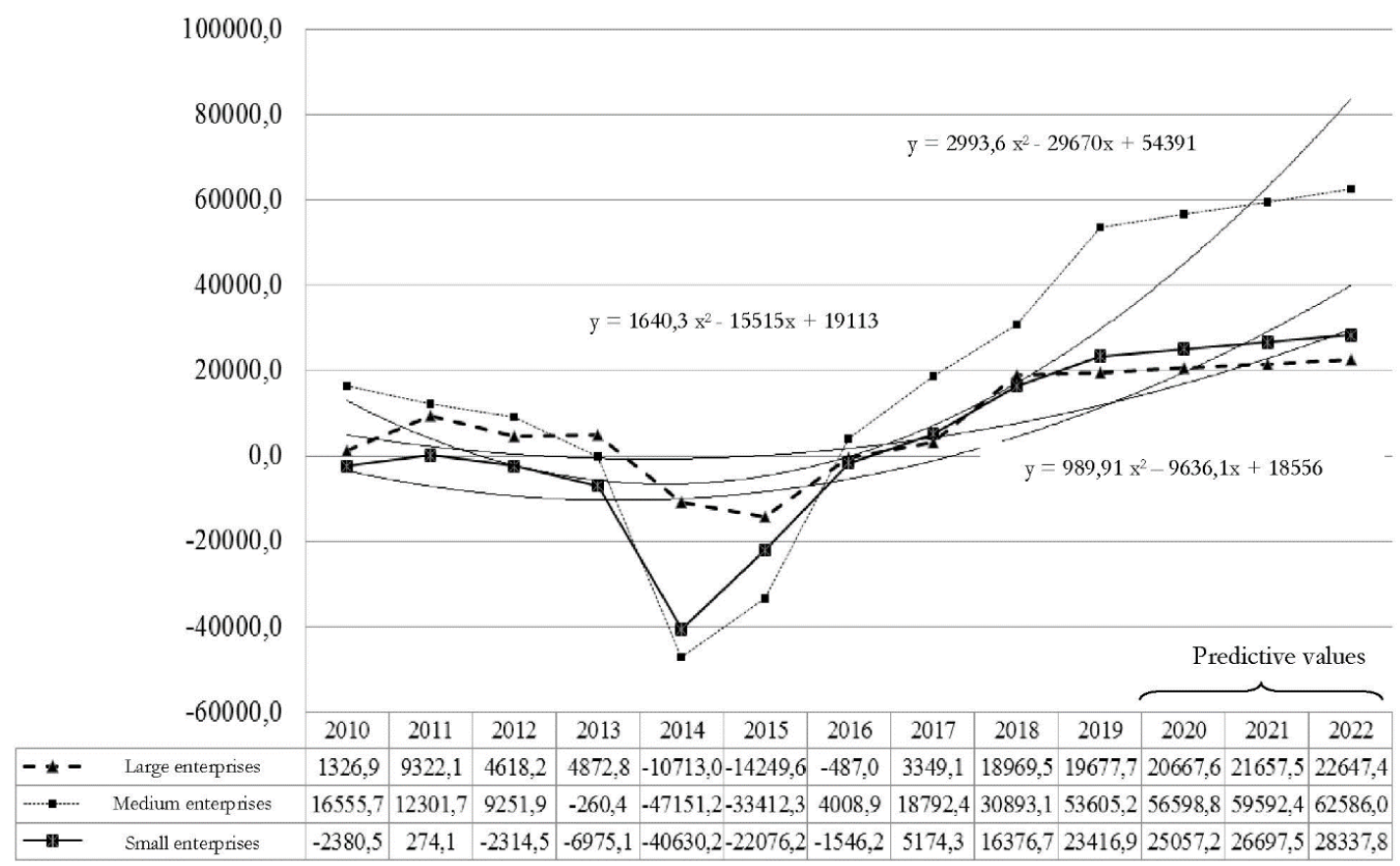

Fig. 2. Financial results (balance) before taxation of wholesale trade enterprises with a division into large, medium and small for 2010-2019 and forecast values 2020-2022.

According to the analysis of financial results (balance) before taxation of wholesale trade enterprises (Fig. 1), it was found that the financial results of wholesale trade enterprises during the studied periods as a whole grew 6.2 times, the average annual growth is 5623.9 million UAH. An increase in the value of this indicator means that enterprises that made more profit than enterprises operated at a loss. But as can be seen from the dynamics, the profitability of enterprises grew quite unevenly, directly indicating an unfavourable economic situation, and hence the presence of financial risks. This is especially true in the period from 2013 to 2015, where, although with significant fluctuations, the enterprises were unprofitable.

This is due to the crisis processes of this period, which increasingly worsened Ukraine's position in the world economy in the medium term (Ukrajina, 2014). The situation changed in 2016, when companies became profitable and its level was constantly growing.

The activity of large enterprises was mainly profitable, in general, for the period under study, the financial result (balance) increased 14.8 times, which is a significant result. However, as indicated by the dynamics of financial results (balance) before tax, the profitability of enterprises in this group also fluctuated over the years, and from 20142016. The average loss for the period was at the level of UAH 8,483.2 million. The average annual growth of the financial balance also indicates a rather slow increase in the level of profitability of enterprises (UAH 989.91 million). 
The most profitable in the group of enterprises, distributed by size, were mediumsized enterprises. Their share in the total on average for the study period was $76.1 \%$. In general, the financial balance for the period under review increased 3.2 times. Period from 2013-2015. It was unprofitable for enterprises, as evidenced by the results obtained. The last four years of the study period were profitable, and profits grew gradually, without declines or fluctuations. The average annual growth of the financial balance indicates an increase in the level of profitability of enterprises, namely 299.36 million. UAH.

A rather difficult financial situation has developed for small enterprises. Almost from 2010 to 2016, the company operated at a loss, except for 2011 in which the profit amounted to 274.1 million UAH. Over the past three years, small businesses have been profitable, the level of profit in 2019. Compared to 2017, grew 4.5 times, which indicates a positive trend. However, according to these indicators, enterprises are in a very difficult situation. Given the current economic situation, the efficiency and financial condition of small businesses, is in a rather difficult position, and without government assistance, most businesses are in bankruptcy.

In 2019, a several of factors indicated a possible period of turbulence for the Ukrainian economy, but the COVID-19 coronavirus pandemic significantly worsened forecasts. Quarantine impact on business, the labour market, exacerbated all the shortcomings of the Ukrainian economic model (Radchuk, 2020).

Data on the financial performance of enterprises is the basis for tactical and strategic management decisions in order to improve the efficiency and competitiveness of enterprises in conditions of market competition and uncertainty in the external management environment (Marmul, 2018). Based on the data obtained from the financial statements according to the given methodology for quantitative risk assessment of enterprises of various sizes.

First of all, sets of values for individual years are analyzed, their distribution, and it that financial indicators can be described by the usual distributions confirmed. Second, descriptive statistics are used as a tool to determine the overall financial health of wholesalers.

Data on the financial performance of enterprises are the basis for tactical and strategic management decisions in order to improve the efficiency and competitiveness of enterprises in conditions of market competition and uncertainty in the external management environment (Marmul, 2018).

Most scholars focus on two main aspects of business management: socioeconomic management and business performance management. Among the methods of socio-economic management of the enterprise are observed: material and moral incentives for personnel; social regulation; economic calculation; balance method; method of financing; price regulation; lending. The second aspect of business management, aimed at managing the efficiency of economic activity, is characterized by the achievement of the necessary discursive effect that will directly ensure the interests of the owners of the enterprise (Hodiashchev, 2017).

Therefore, the company needs to strengthen control and increase the level of current liquidity, the level of asset turnover and the ratio of debt to equity capital, reduce short-term and long-term liabilities and increase equity capital, reduce the number of 
investment projects financed by borrowed capital, revalue non-current assets and increase contributions of founders to the assets of the enterprise (Lukashevich, Konnikov, 2018).

Financial risks arising from cost overruns can become an obstacle that prevents an enterprise from meeting its financial obligations. Nowadays every business is exposed to a certain level of financial risk. Business leaders need to reduce financial risks in order to maintain healthy cash flow (Prokhorova, at al., 2019).

First of all, these sets of values for individual years are analyzed, their distribution, and it is confirmed that financial indicators can be described by the usual distribution. Second, descriptive statistics are used as a tool to determine the overall financial health of wholesalers. To find ways to reduce risks, it is necessary to correctly interpret the significance of features in the potential function of the integral assessment of financial potential. It is necessary to identify management priorities in the potential functions of the system indicators built according to the corresponding blocks. Therefore, first, the analysis of the potential function of the integral assessment of the level of financial potential is carried out. The block that occupies the largest specific weight in the structure of the potential function of the integral assessment of financial potential and will be the block that should be strengthened. The next step is to analyze the weight of the features in the potential function built according to the indicators of this block, then the next indicator of the same function with a lower weight, etc. Based on the results of ranking the blocks and indicators corresponding to each of the blocks presented, the priorities in the management of the financial risk of the enterprise are ranked to determine the directions of their minimization and search for ways to increase the financial potential (Tab. 5).

Table 5 Ranking priorities in financial sustainability management

Integral assessment $(\tilde{y})=0,24 \mathrm{y}_{1}+0,42 \mathrm{y}_{2}+0,74 \mathrm{y}_{3}+0,13 \mathrm{y}_{4}$

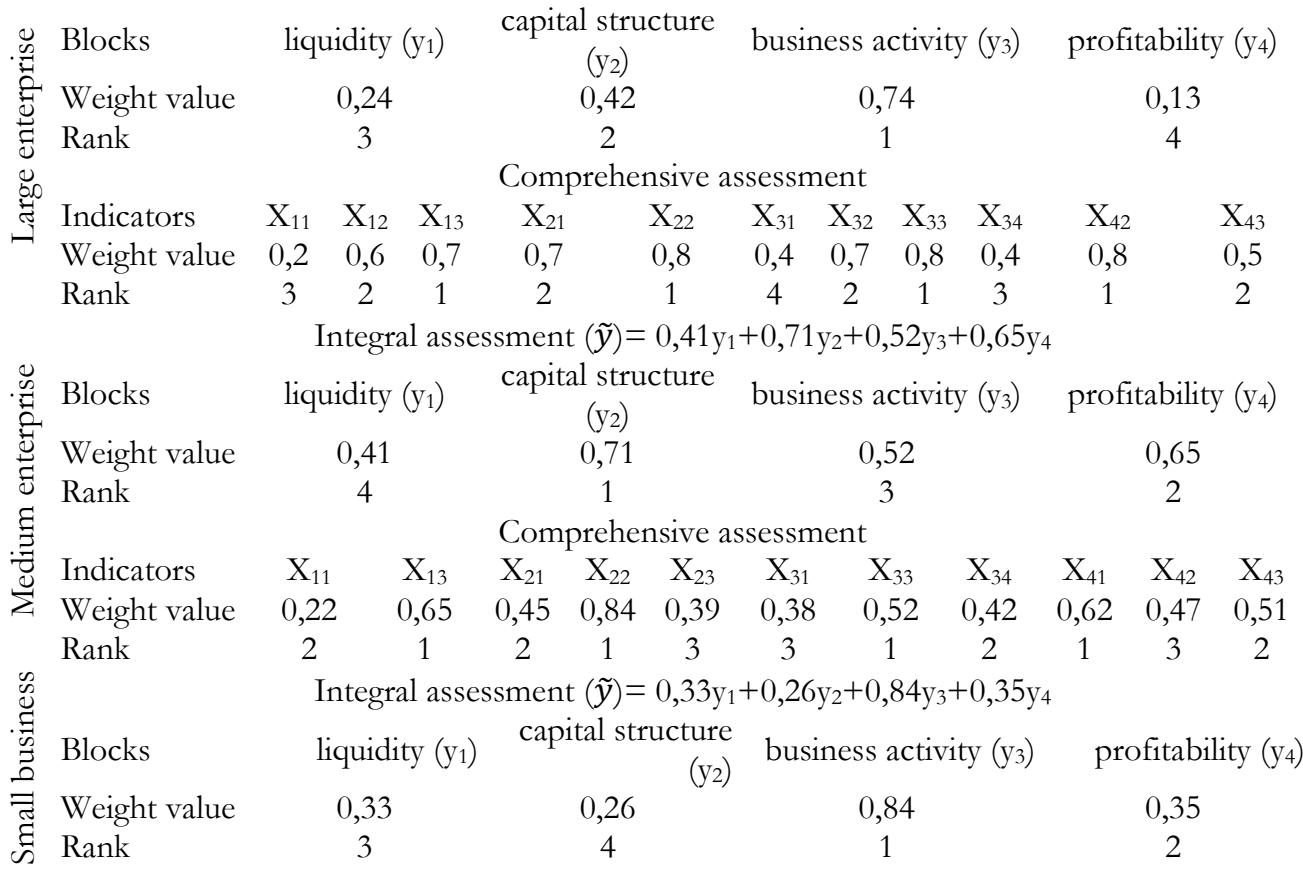




\begin{tabular}{lcccccccccc}
\multicolumn{11}{c}{ Comprehensive assessment } \\
Indicators & $\mathrm{X}_{12}$ & $\mathrm{X}_{13}$ & $\mathrm{X}_{21}$ & $\mathrm{X}_{23}$ & $\mathrm{X}_{32}$ & $\mathrm{X}_{33}$ & $\mathrm{X}_{34}$ & $\mathrm{X}_{41}$ & $\mathrm{X}_{42}$ & $\mathrm{X}_{44}$ \\
Weight value & 0,25 & 0,86 & 0,92 & 0,23 & 0,83 & 0,05 & 0,55 & 0,65 & 0,52 & 0,41 \\
Rank & 2 & 1 & 1 & 2 & 1 & 3 & 2 & 1 & 2 & 3
\end{tabular}

By ranking the priorities in the financial risk management system, the company's management will decide the issue of finding the main directions for minimizing and eliminating financial risks. This is necessary to stabilize financial and economic development and will allow you to quickly respond and adapt to changes in the external environment. The enterprise should be more flexible in the event of negative consequences from the onset of risky situations for the timely reorientation of the goals of entrepreneurial activity. The ranking of priorities in financial stability management showed that the business activity block ranks first among the blocks of financial coefficients for quantitative risk assessment of enterprises.

Indicators of business activity of an enterprise allow us to assess its financial condition, help to identify strengths and weaknesses, strategic development, characterizing the use of potential and determine the position of the enterprise in the market, its competitiveness.

Therefore, among the directions of increasing the business activity of the enterprise, we can single out the following. Acceleration of the rotation of the resources of the enterprise and the reduction of the period of their turnover is possible due to the reduction of the period of circulation or the period of production. Reducing the production period is achieved through the introduction of innovative technology and production automation. Reducing the period of circulation requires rationalization and effective use of available resources, improving document flow.

Using the methods of socio-economic management of the enterprise, which take into account the material motivation of employees and moral incentives, the management of the enterprise will increase the level of labour productivity. An important role in increasing the profitability of a trading enterprise belongs to increasing the growth rate of income from the sale of goods by improving trade services and stimulating the development of modern sales channels.

Achievement of increasing the level of profitability is possible by optimizing the management of operating costs (Voronina, 2019). To optimize operating costs, it is necessary to introduce competitive enterprise strategies and apply effective management tools. In order to increase productivity, it is necessary to develop various schemes of rewards and incentives. Upgrading the skills of employees will be beneficial in the long term. An effective way to increase profits is through repeat sales, which is achieved through an effective marketing strategy engine.

The next block for ranking priorities in the financial risk management system is occupied by the block of liquidity indicators. The main measures to increase the liquidity of the enterprise are (Nazarova, 2016): stimulating the sale of primary products; planning and forecasting the required amount of liquid funds by accounting for payments due and cash receipts; ensuring the acceleration of the turnover of monetary assets; restructuring of accounts payable; improvement of dividend policy; direction of profit to replenish its own working capital; determination of the minimum required need for cash assets for 
current economic activities; mobilization of internal reserves of self-financing; refinancing of receivables; attraction of additional share (equity) capital.

The indicators of the capital structure block rank fourth among the priorities in financial stability management. There is no single method for optimizing the capital structure; each enterprise, based on the existing economic and financial situation, must choose one of the methods that would correspond to the current situation and the desired result of the enterprise (Korzh, at al., 2017).

The main source of additional capital attraction for trade enterprises is the capitalization of net income, an increase in commodity credit, and attraction of bank loans. Replenishment of equity capital from external sources can be carried out by increasing the authorized capital; this direction is most often used by trade enterprises.

The most appropriate standard for traders is the compliance of the capital structure with the compromise (moderate) type of financial assets policy. It is advisable to take this standard as an auxiliary one, which will ensure the growth of the company's value while maintaining the required level of its financial stability. An important aspect of optimizing the capital structure is the improvement of the methodological foundations for assessing the cost of capital (Sytnyk, 2013).

Thus, capital structure management is the process of finding the optimal solution for choosing between the level of risk and return. Optimization of the capital structure consists in minimizing costs in the case of attracting long-term sources of financing and ensuring the maximum effect on investment.

Based on the study, it can be stated that in the modern conditions of an unstable market economy, the influence of financial risks on the activities of enterprises is not uniform, but its influence cannot be avoided by any enterprise, regardless of size and financial capabilities. Timely identification, neutralization of financial risks and their management is one of the main tasks in the effective management of the financial activities of an enterprise to prepare for future developments.

\section{Conclusion}

During the study period, the absolute value of financial results for wholesale enterprises was mainly positive, a loss was noted only in 2013-2015. The loss on them during this period is due to both an increase in loss in the group of unprofitable enterprises and a decrease in profit in the group of profitable economic entities. The predicted values of financial results (balance) before taxation of the activities of wholesale enterprises with distribution into large, medium and small, indicate that, in general, the profitability of enterprises will increase by $10.9 \%$. The profitability of large enterprises will grow by $9.6 \%$, the profitability of medium-sized enterprises will increase by $10.6 \%$, and the profitability of small enterprises will increase by $13.1 \%$. However, the crisis in the country's economy and the unforeseen consequences of the COVID-19 coronavirus pandemic may significantly worsen the forecast data. This situation will have the greatest impact on small businesses that are already at risk. The growing pressure of the crisis state and insecurity on the part of the state will lead to a transition from the crisis state, in which enterprises are today, to a state of economic bankruptcy. 
Therefore, modern theory and practice of management requires the creation of new, effective scientific and methodological approaches to assessing the effectiveness of management in the areas of financial and economic activities. In particular, the formation and use of financial resources of enterprises based on the consistency and complexity of the adoption and implementation of management decisions.

The results of calculating the integral assessment of financial risk at enterprises indicate that large enterprises are in an acceptable risk zone and are in the range of 0.27 0.44. Which indicates a weak threat of a crisis. The enterprise maintains its economic stability. However, one of the blocks does not match the reference one. The potential level remains at the limit $(0.55-0.72)$ during the study period.

Medium-sized enterprises have a level of financial risk in the range of 0.23-0.24. This indicates a weak threat of a crisis. The enterprise has a fairly high level of profitability and business activity and high financial potential (0.76-0.78).

Small-sized enterprises are in a critical risk zone and show the level of financial risk in the range of $0.54-0.67$. This indicates that the economic viability of the enterprise is under threat. There is a fairly low level of business activity, the amount of accounts receivable and the duration of the period of its turnover are growing. The level of financial potential is $0.32-0.45$.

Further directions of scientific research will be aimed at researching and developing an effective mechanism for managing the financial stability of an enterprise. Identifying its main tools and levers that affect the efficiency and productivity of its activities and can stimulate its development. Research in this area will help enterprises to improve their competitiveness, avoid financial risks and adapt to changes in the macro environment.

\section{References}

Agnieszka, M., Chomicz-Grabowska, Lucjan, T. Orlowski (2020). Financial market risk and macroeconomic stability variables: dynamic interactions and feedback effects. Journal of Economics and Finance. № 44, 655-669.

Aref'jeva, O.V., Mjaghkykh, I.M., Jashhuk, A.M. (2019). Problems and ways to improve the management of financial activities of the enterprise by minimizing risks. Visnyk KNUTD, 1(131), 49-57 [in Ukrainian].

Bjelousova, S.V. (2017). Formation of an enterprise financial risk management program. Naukovyj visnyk Uzhghorodsjkogho nacionaljnogho universytetu,12(1), 33-37 [in Ukrainian].

Daniela, Bragoli, Flavia, Cortelezzi, Giovanni, Marseguerra, Massimiliano, Rigon (2020). Innovative investments, financial imperfections, and the Italian business cycle. Oxford Economic Papers. Vol. 72, Issue 2. 412-434.

Dermenzhi, D.F. (2018). Determination of the essence of financial risks and the main methods of their assessment in an unstable market economy. Prychornomorski ekonomichni studii, 25,71-74 [in Ukrainian].

Dervis, Kirikkaleli (2019). Time-frequency dependency of financial risk and economic risk: evidence from Greece. Journal of Economic Structures. Vol. 8, URL: https://journalofeconomicstructures.springeropen.com/articles/10.1186/s40008-019-0173-z

Dombrovska, S.O. (2016). The influence of financial risk on the financial management system of an enterprise. Visnyk sotsialno-ekonomichnykh doslidzhen. Odesa, 2 (61),184-193 [in Ukrainian]. 
Gherasymova, I.Ju. (2016). Financial risk management of an insurance company with a view to secured economic security. Ekonomichnyj prostir, 115, 112-125 [in Ukrainian].

Ghranaturov, V.M. \& Lytovchenko, Y.V. (2004). Business risk management: theory and practice: monograph. O.: MChP« «ven», 2005 [in Russian].

Hodiashchev, M. (2017). The management of business activity of enterprises: scientific and economic analytics. Journal of Economic Studies, Vol. 3(4), 38-44.

Korzh, N., Mostenska, T. \& Bilan, Y. (2017). Resource-based view in managing financial component of corporate capital. Polish journal of management studies, Vol.16(2), 133-146.

Kuzjminecj, T.Gh. \& Pereghnjak, Ju.A. (2017). Management of financial risks of an enterprise in a market economy. Molodyj vchenyj, 12 (52), 677-680 [in Ukrainian].

Law of Ukraine on Entrepreneurship. № 1481-III. (2000, February 22). Vidomosti Verkhornoyi Rady Ukrayiny, 14, 168 [in Ukrainian].

Lukashevich, N. \& Konnikov, E. (2018). Approach to assessment of financial stability of industrial enterprises as a basis of sustainable development. St. Petersburg State Polytechnical University Journal. Economics. Vol. 11(2), 92-100.

Marmul, L. (2018). Financial results of the enterprises activities and their use in management. Ekonomichnyj visnyle universytetu, 39, 144-151.

Michael R. Lewis (2020). How to Reduce Financial Risk. wikiHow. URL: https://www.wikihow.com/ReduceFinancial-Risk.

Mihoci, A., Althof, M., Chen, C.Y.-H. \&Härdle, W.K. (2020). FRM Financial Risk Meter. Advances in Econometrics. Vol. 42. pp.335-368.

Nazari, R. \& Asgar Zamani, A. (2018). Reducing the financial risk and increasing the output by adopting and suitable locating of financial strategies. European Journal of Sustainable Development, Vol. 7, 1, 75. URL: https://doi.org/10.14207/ejsd.2018.v7n1p75

Nazarova, T. (2016). Financial capacity of industrial enterprise. Journal of Economic Studies, Vol. 2(3), 141-145.

Olga, Sosnovska, Maksym, Zhytar. (2018). Financial architecture as the base of the financial safety of the enterprise. Baltic Journal of Economic Studies, 4, 334-340. https://doi.org/10.30525/2256-0742/20184-4-334-340.

Orlyk, O.V. (2016). Financial risks in the system of ensuring the financial and economic security of the enterprise. Innovacijna ekonomika, 5-6, 218-223 [in Ukrainian].

Portovaras, T.R. (2018). Methodological aspects of the analysis of financial risks as a tool for managing them. Svit finansiv, 3 (56), 128-140 [in Ukrainian].

Prokhorova, V., Mushnykova, S., Bytiak, O. \& Slastianykova, K. (2019). Management of financial risks in the security system of enterprise development: economic and legal aspects. SHS Web of Conferences 67, 06043, 67(7), URL: https://doi.org/10.1051/shsconf / 20196706043.

Pustovghar, S.A. \& Rudachenko, O.A. (2019). Model of preventive diagnostics of financial risk of a state enterprise. Investyciji: praktylka ta dosvid, 20, 61-65 [in Ukrainian].

Radchuk, O. (2020). Leap autumn - 2020: five main economic threats for Ukraine. Slovo $i$ dilo. URL:https://www.slovoidilo.ua/2020/07/28/kolonka/ aleksandrradchuk/ekonomika/vysokosna-osin-2020-pyat-holovnyx-ekonomichnyx-zahroz-ukrayiny [in Ukrainian].

Shura, N.O. (2016). The practice of assessing and changing financial risks in the activities of public joint stock companies. Aghrosvit,11, 29-37 [in Ukrainian].

Shyshkina, O.V. (2016). Methods for minimizing and neutralizing financial risks: theoretical and applied aspects. Problemy i perspektyvy ekonomiky ta upravlinnja, 4 (8),176-181 [in Ukrainian].

Sievidova, I. (2018). Research-based strategy formation using non-cooperative game theory tools. Efektyrna ekonomika, 3. URL: http://www.economy.nayka.com.ua/?op=1\&z=6285 [in Ukrainian].

Sytnyk, H. (2013). Capital structure optimization of trade enterprises. Herald of KNUTE, 6, 68-83.

Tkachuk, H.O. (2015). Identification of economic risks in the accounting and analytical system of the enterprise. Ekonomika kharchovoi promyslovosti, Vol. 7, 4, 80-88 [in Ukrainian].

Tsintsadze, A., Glonti, V., Oniani, L., \& Ghoghoberidze, T. (2019). Empirical analysis of financial and nonfinancial risks of the commercial bank. European Journal of Sustainable Development, 8(2), 101. https://doi.org/10.14207/ejsd.2019.v8n2p101.

Ugrimova, I., Kraivska, I. \& Gryshchenko, A. (2016). Risk assessment in system of small businesses crisis management. Visnyk Pryazovsjkogho derz̧havnogho tekhnichnogho universytetu, 32, Vol. 1, $20-26$. 
Ukrajina - 2014: socialjno-ekonomichna kryza ta poshuk shljakhiv reformuvannja. (2014). Eksperty pro stan i perspektyvy ekonomiky Ghromadjany pro sytuaciju u krajini, pro vladu, jiji pidtrymku i vidpovidaljnistj. URL: https://razumkov.org.ua/upload/2014_Ekonomika_101114_NNN.pdf [in Ukrainian].

Vitalina, Delasa, Euvgenia, Nosova \& Olena, Yafinovycha (2015). Financial Security of Enterprises. Procedia Economics and Finance, 27, 248-266.

Voronina, V.L. (2019). Assessment of the results of managing the economic activity of trade enterprises of Ukraine. Infrastruktura rynku, 27, URL: http://dspace.pdaa.edu.ua:8080/handle/123456789/2834 [in Ukrainian].

Yang, Pengbo \& Zhang, Hanyu (2018). Identification of Financial Risks based on Artificial Intelligence. International Journal of Science and Research. Vol.7 Issue 8. 619-621.

Yuxiao, Ye, Andy, C.L., Yeung \& Baofeng, Huo (2020). Maintaining stability while boosting growth? The long-term impact of environmental accreditations on firms' financial risk and sales growth. International Journal of Operations \& Production Management, Vol. 40, 12, 1829-1856.

Zaika, S., Hridin, O., Sievidova, I. \& Mandych, O. (2020). Financial risks of broker's activity. Financial and credit activity: problems of theory and practice. Vol. 33(2), 149-158. 